10.1590/S1414-40772018000300009

Este é um artigo publicado em acesso aberto sob uma licença Creative Commons

https://creativecommons.org/licenses/by-nc/4.0/

\title{
Internacionalização da educação superior: uma análise das tendências de mobilidade dos estudantes entre países do norte e do sul global
}

\author{
Marialva Moog Pinto ${ }^{1}$ \\ Enrique Martínez Larrechea ${ }^{2}$
}

Resumo: O processo de internacionalização da Educação Superior (ES) apresenta cada vez mais centralidade na dinâmica de desenvolvimento desse setor e se expressa em diversas respostas por meio das quais os sistemas e as instituições tentam fazer frente aos desafios da globalização e da regionalização. Embora a internacionalização não se reduza ao fenômeno da mobilidade estudantil, esta tem sido uma das formas mais visíveis e impactantes. Esse artigo tem como objetivo descrever e interpretar tendências da mobilidade internacional de estudantes da ES e analisar essas tendências de mobilidade entre regiões globais e na sua relação com o Brasil. Para atingir o objetivo, fizemos revisão da literatura especializada, de documentos de políticas e institucionais, assim como bases de dados estatísticos internacionais. Ao discutir, o artigo justifica que os mecanismos de mobilidade criados são inconsistentes, resultando muitas vezes na transferência de recursos financeiros significativos dos países em desenvolvimento para os países desenvolvidos.

Palavras-chave: Internacionalização da Educação Superior. Mobilidade estudantil. Sul Global. Brasil.

\section{Internationalization of higher education: an analysis of mobility trends of students between north and south global countries}

Abstract: The process of internationalization of Higher Education (ES) is increasingly central to the development dynamics of this sector and is expressed in several responses through which systems and institutions try to meet the challenges of globalization and regionalization. Although internationalization is not limited to the phenomenon of student mobility, this has been one of the most visible and impactful forms. This article aims to describe and interpret trends in the international mobility of ES students and to analyze these mobility trends between global regions and their relationship with Brazil. To achieve this goal, we have reviewed the literature, policy and institutional documents, as well as international statistical databases. In discussing, the article justifies that the mechanisms of mobility created are inconsistent, often resulting in the transfer of significant financial resources from developing to developed countries.

Key words: Internationalization of Higher Education. Student mobility. Global South. Brazil. 
Internacionalização da educação superior: uma análise das tendências de mobilidade dos estudantes entre países do norte e do sul global

\section{Introdução}

Os sistemas nacionais de educação superior dos países em desenvolvimento - como é o caso do Brasil e dos países da América Latina e Caribe - vem passando ao longo das últimas três décadas por um intenso processo de transformação. Esse processo multidimensional tem a ver com a expansão da matrícula na educação superior, de maneira convergente com a experiência de outras regiões do mundo, como as da Norte América, da Europa, da Ásia e da África. Essa expansão demográfica gerou uma forte diferenciação interna nos sistemas de educação superior. Hoje, para além do tradicional setor universitário, surgiram instituições de educação superior que não são universidades e relacionadas ao setor público. Houve, enfim, uma multiplicação de instituições privadas de ensino superior. A presença de diversos formatos institucionais, entre os quais a universidade é apenas um deles, tornou mais complexa a economia política dos sistemas de educação superior.

Outro fator significativo são as políticas impostas pelas agências internacionais, como a OCDE, a Organização das Nações Unidas para a Educação a Ciência e a Cultura (UNESCO), o Banco Mundial, que pensam também no futuro da Educação Superior e veem nos países do hemisfério sul um grande potencial para ocupar as vagas ociosas das universidades europeias em especial e as da América do Norte.

Assim são sanadas duas dificuldades: a primeira e mais importante para os macroatores sociais é que as universidades do hemisfério norte conseguem seguir se mantendo em funcionamento pelo grande número de estudantes estrangeiros que os países enviam para estudar nos países desenvolvidos; e a segunda é a possibilidade de gerar intercâmbio de conhecimento, melhorando a formação dos estudantes dos países em desenvolvimento, que geralmente são países com pouco investimento em educação e que pagam para enviar uma parcela dos seus jovens para formar-se. Nesse segundo caso, alguns jovens brilhantes podem não retornar ao seu país de origem, sendo capturados pelos países desenvolvidos para fazer parte de empresas, pesquisas, etc.

\section{Metodologia}

A metodologia de abordagem da questão da mobilidade se apoia na revisão da literatura sobre a internacionalização da educação superior, em especial aquela relativa à mobilidade acadêmica, o que permitiu contar com categorias analíticas e interpretativas relevantes. Também se fez a análise de documentos institucionais e de políticas, procurando contar com categorias conceituais dessa fonte. Finalmente, trabalhando com bases de dados 
internacionais, procurou-se estabelecer a descrição e a comparação dos fluxos de mobilidade entre algumas origens e destinos especialmente relevantes, principalmente relativos aos Estados Unidos, aos países desenvolvidos da Organização para a Cooperação e Desenvolvimento Econômico(OCDE), aos países da Comunidade de Países de Língua Portuguesa (CPLP) na sua relação com Brasil, e aos países de América do Sul, também na sua relação como o Brasil.

O presente artigo tem como objetivo a descrição e a interpretação das tendências da mobilidade internacional de estudantes e a análise das tendências da mobilidade no Brasil e na região latino-americana.

As perguntas centrais da pesquisa incluem a determinação da magnitude relativa do fenômeno da mobilidade, a análise dos pontos de origem e destino desses estudantes internacionais e a importância ou não do Sul Global nos fluxos dos estudantes internacionais. Adicionalmente, quais são as consequências das políticas de internacionalização consistentes com essas tendências de mobilidade? E quais são os benefícios para os países em desenvolvimento em relação à mobilidade dos estudantes?

\section{Técnicas de coleta e interpretação dos dados}

Este estudo é de abordagem qualitativa, porém se utiliza dos dados quantitativos fornecidos por estatísticas da OCDE, da Organização das Nações Unidas para a Educação, a Ciência e a Cultura (UNESCO) e do Centro Interuniversitario de Desarrollo (CINDA), nos anos de 2010, 2014 e 2016, respectivamente. A análise documental exploratória se desenvolveu com base nos documentos fornecidos por meio da busca sobre os descritores "Internacionalização da ES" e "Mobilidade estudantil na ES".

Para a análise dos dados explorados, realizou-se uma abordagem de cunho interpretativo e uma análise do conteúdo.

\section{Globalização e internacionalização}

A globalização é um fenômeno civilizatório maior que atingiu, nos últimos vinte anos do séc. XX, um estágio de desenvolvimento intenso, decorrente dos avanços da microeletrônica e da cibernética. A "sociedade informacional" - ou a "sociedade do conhecimento" - está sustentada no desenvolvimento da internet e dos múltiplos processos econômicos, culturais e políticos baseados nessas tecnologias. 
Internacionalização da educação superior: uma análise das tendências de mobilidade dos estudantes entre países do norte e do sul global

As origens da globalização podem se situar, segundo diversos olhares, em momentos diferentes. Uma caracterização possível dessas origens é como fenômeno decorrente do final da guerra fria e de uma estrutura econômica e tecnológica que fez possíveis os fenômenos que têm uma nova abrangência mundial, incorporando todos os países numa dinâmica global até certo ponto compartilhada. Nesse sentido, a globalização não está sujeita à escolha dos sujeitos, como não o esteve o cristianismo medieval ou a revolução industrial. Ela é decorrente de processos culturais, econômicos e tecnológicos resultantes do desenvolvimento de forças produtivas e culturais que estão para além das preferências ideológicas, políticas ou valorativas dos sujeitos.

No entanto, os processos de internacionalização da educação superior é uma das respostas dadas pelos sujeitos situados em diversos níveis de análise do fenômeno da globalização, sejam estes professores, estudantes, instituições, universidades, governos e sistemas nacionais de educação superior (KNIGHT, 2012).

Embora a "internacionalização" tenha sido possível depois da criação dos estados nacionais, a universidade sempre foi cosmopolita e transcultural, na medida em que o ser humano, curioso e voltado à indagação do mundo, sempre tentou ampliar sua geografia imediata à procura do desconhecido, por querer saber mais, conhecer mais e consequentemente melhorar a sua condição.

Segundo Laus (2012, p. 132), “tradicionalmente dirigidas à Europa e aos EUA, as relações acadêmicas também passaram a pautar-se pelas orientações da política externa do governo instalado no país a partir de 2003, baseada na consolidação do multilateralismo”.

\begin{abstract}
Nesse sentido, voltaram-se complementarmente para países emergentes como Índia, China e África do Sul e a dar seguimento e ampliação àquelas já existentes com seus parceiros tradicionais, a Europa e EUA bem como a América Latina, onde se intensificaram mais especificamente as relações com a América do Sul. Tais ações estão atreladas às transformações ocorridas na geopolítica internacional na década de 1990, quando o mundo assiste à queda no bipolarismo e ao surgimento de uma nova ordem de caráter ocidental. Essa se caracteriza pela transnacionalização produtiva, por normas internas comuns de pluralismo democrático para todas as sociedades e pelo predomínio do liberalismo econômico como marco tanto para a economia internacional como para a consecução das políticas de ajustes nos Estados. Tais fatores passaram a pautar a formulação e implementação da política exterior brasileira e sua opção pela cooperação Sul-Sul, caracterizada por Ayllón (2010) como o fluxo de recursos e de capacidade técnica entre países em desenvolvimento e que está impulsionada por dois fatores simples: esses países contam com uma enorme bagagem de conhecimentos técnicos para compartilhar com seus pares e buscam soluções nas experiências dos demais (LAUS, 2012, p. 132).
\end{abstract}

A expansão neocolonial dos países industrializados ao longo dos séculos XIX e XX, uma cena fundante da posterior globalização - teve compensações materiais enormes e construiu no final do século XX, e ainda hoje, um mundo fortemente estratificado em termos de poder e conhecimento científico tecnológico. 
Em certo sentido, na fase da globalização no final do século XX e início do século XXI, novas estratégias de internacionalização assimétrica da educação superior são formuladas pelos países com maior desenvolvimento dos seus sistemas de ensino superior e de educação a distância (Inglaterra, Austrália, Nova Zelândia, Estados Unidos, Canadá) e pelos sistemas científico-tecnológicos que atraem, pelo seu grau de avanço, os de outros países (Inglaterra, Estados Unidos).

Com o fenômeno da globalização, a internacionalização se amplia em todas as áreas, porém, no âmbito da Educação Superior, o fenômeno alcança modalidades inéditas. Segundo Hargreaves (2003, p. 4), "na sociedade em constante transformação e autocriação, o conhecimento é um recurso flexível, fluido, em processo de expansão e mudança incessante".

O processo de internacionalização da Educação Superior apresenta cada vez mais centralidade na dinâmica de desenvolvimento desse setor e se expressa em diversas respostas por meio das quais os sistemas e as instituições tentam fazer frente aos desafios da globalização e da regionalização. Algumas dessas formas são os intercâmbios institucionais, a cooperação em pesquisas e os programas de ensino, na mobilidade de docentes e estudantes, nas redes de trabalho e no estabelecimento de estratégias, de instituições e até de campi voltados para os contextos regionais e internacionais. Embora a internacionalização não se reduza somente ao fenômeno da mobilidade estudantil, esta tem sido uma das formas mais visíveis e impactantes da internacionalização da ES.

O fenômeno vem sendo estudado em âmbito global e também nas regiões da América Latina e do Caribe. Diversos pesquisadores e centros de pesquisa têm desenvolvido produções relevantes focadas nas seguintes dimensões: das políticas públicas de promoção da internacionalização da ES; da avaliação e do seguimento dos programas; da descrição das magnitudes - insumos e produtos; do balanço das políticas; das normativas; da mobilidade estudantil; e das migrações científicas. Por vezes, as análises focaram o plano do sistema; em outros casos, se concentraram nas políticas institucionais (FERNÁNDEZ LAMARRA; ALBORNOZ, 2014).

A internacionalização da Educação Superior visa eliminar barreiras e fronteiras de conhecimento entre as nações; esse processo, no entanto, não é equilibrado nem homogêneo. A internacionalização da ES se constrói desde diversas perspectivas, algumas delas fortemente assimétricas, em geral ligadas à ideia da Educação como um bem rentável e como mercado; e outras voltadas para a cooperação e a partilha de recursos. 
Internacionalização da educação superior: uma análise das tendências de mobilidade dos estudantes entre países do norte e do sul global

\section{Mobilidade de estudantes e internacionalização}

O fenômeno da mobilidade internacional de estudantes de nível superior se apresenta como uma das dimensões mais significativas da internacionalização. O crescimento global de longo prazo vai de 0,8 para 4,1 milhões de estudantes de nível terciário nos últimos quarenta anos. O crescimento foi particularmente acelerado entre 2005 e 2013, quando passou de 2,8 para 4,1 milhões (UNESCO, 2015).

\section{Gráfico 1 - Crescimento global de estudantes internacionais de nível terciário}

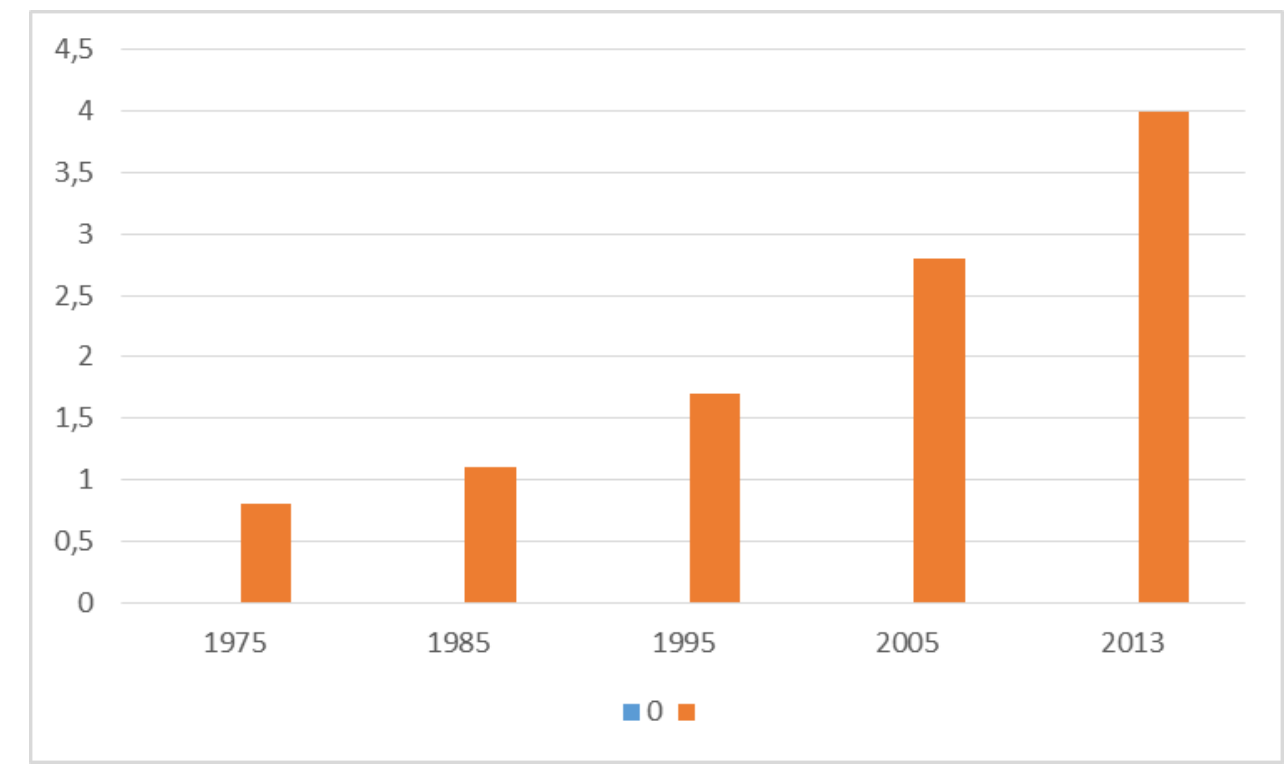

Fonte: Elaborado pelos autores com base nos dados do Instituto de Estatística da UNESCO (2015).

Em 2012, cinco países contavam com mais de 10 mil estudantes de doutorado no exterior. Dois países em desenvolvimento do G20, membros do BRICS, China e Índia lideravam essa tendência. A China com quase 60 mil estudantes, seguida da Índia com mais de 30 mil. Com contingentes entre 11 mil e 13 mil, Alemanha, Irã e Coreia ocupavam um segundo nível. Outros dez países: Itália, Canadá, Estados Unidos e França, entre os desenvolvidos, e Arábia Saudita, Indonésia, Vietnã, Turquia, Paquistão e Brasil, entre os emergentes, superavam os 4 mil estudantes internacionais fora de suas fronteiras.

Segundo dados do escritório de estatística da UNESCO, só dez países concentravam quase $90 \%$ da mobilidade internacional de estudantes de doutorado recebidos nos campos das ciências e das engenharias. Os Estados Unidos recebem quase o 50\% do total. Os outros países que concentram a mobilidade são Reino Unido, França, Austrália, Canadá, Alemanha, Suíça, Japão, Malásia e Suécia (num ranking entre 2 e 9\%) (UNESCO, 2010). 
No caso da América Latina, segundo dados de CINDA (2016), com exceção de Cuba (e de Espanha e Portugal na região ibero-americana), entre 1999 e 2014 todos os países tiveram saldos negativos, isto é, os estudantes nacionais que saem representam um número significativamente maior em comparação com os estudantes estrangeiros que chegam. Alguns desses saldos negativos são de (-)15 mil estudantes (Brasil e México); em outros, na ordem de (-)1 mil, como Costa Rica e Uruguai.

Argentina, Brasil, Chile, Equador, México e Venezuela, juntos, apresentam um saldo bruto de mobilidade negativa que é, na média anual, de quase (-)73 mil estudantes.

No início do processo de internacionalização da ES, a mobilidade estudantil estava centrada nos programas de pós-graduação stricto sensu, no entanto, na década de 1990 em diante, os países hegemônicos iniciam um processo de ampliação da sua influência sobre o sistema mundial de educação, atraindo estudantes de graduação.

Com base em dados de UNESCO e OCDE, pode-se verificar a magnitude e o sentido dos fluxos da mobilidade internacional de estudantes.

Tabela 1 - Países com maior mobilidade em 2010 e 2014

\begin{tabular}{|c|c|c|c|c|c|}
\hline $\begin{array}{l}\text { Países com } \\
\text { maior } \\
\text { mobilidade }\end{array}$ & $\begin{array}{c}\mathbf{N}^{\circ} \\
\text { Estudantes } \\
\text { enviados }\end{array}$ & $\begin{array}{c}\mathbf{N}^{\mathbf{o}} \\
\text { Estudantes } \\
\text { recebidos }\end{array}$ & $\begin{array}{l}\text { Países que mais } \\
\text { receberam } \\
\text { estudantes dos } \\
\text { países referentes }\end{array}$ & $\begin{array}{c}\text { Em } \\
2010\end{array}$ & $\begin{array}{c}\text { Em } \\
2014\end{array}$ \\
\hline \multirow{10}{*}{$\begin{array}{c}\text { Estados } \\
\text { Unidos }\end{array}$} & \multirow{5}{*}{$\begin{array}{c}\mathbf{2 0 1 0} \\
50.756 \\
\text { OCDE } \\
+ \\
1.813 \\
\text { G20 }\end{array}$} & \multirow{5}{*}{$\begin{array}{c}\mathbf{2 0 1 0} \\
212.835 \\
\text { OCDE } \\
+ \\
270.298 \\
\text { G20 } \\
+ \\
174.742 \\
\text { Demais países }\end{array}$} & Coreia & 71.514 & 1.355 \\
\hline & & & Reino Unido & 15.670 & 14.950 \\
\hline & & & Canadá & 27.896 & 8.049 \\
\hline & & & Granada & & 4.544 \\
\hline & & & Alemanha & 3.922 & 4.523 \\
\hline & \multirow{5}{*}{$\begin{array}{c}\mathbf{2 0 1 4} \\
67.665\end{array}$} & \multirow{5}{*}{$\begin{array}{c}\mathbf{2 0 1 4} \\
907.251\end{array}$} & França & 3.435 & 3.201 \\
\hline & & & Japão & 24.622 & 2.034 \\
\hline & & & México & 13.331 & - \\
\hline & & & Outros... & $\ldots$ & $\ldots$ \\
\hline & & & Brasil & 424 & 663 \\
\hline \multirow[t]{8}{*}{ Reino Unido } & \multirow{4}{*}{$\begin{array}{c}\mathbf{2 0 1 0} \\
33.495 \\
\text { OCDE } \\
+ \\
1.813 \\
\text { G20 }\end{array}$} & \multirow{4}{*}{$\begin{array}{c}\mathbf{2 0 1 0} \\
198.431 \\
\text { OCDE } \\
+ \\
130.942 \\
\text { G20 } \\
+ \\
198.916 \\
\text { Demais países } \\
\end{array}$} & Irlanda & 22.862 & 1.579 \\
\hline & & & Alemanha & 20.157 & 1.798 \\
\hline & & & Polônia & 18.029 & \\
\hline & & & França & $\mathbf{1 7 . 5 8 4}$ & 2.110 \\
\hline & \multirow{4}{*}{$\begin{array}{c}\mathbf{2 0 1 4} \\
31.078\end{array}$} & \multirow{4}{*}{$\begin{array}{c}\mathbf{2 0 1 4} \\
428.724\end{array}$} & Estados Unidos & 15.670 & 9.601 \\
\hline & & & Holanda & 862 & 2.060 \\
\hline & & & Austrália & 1.661 & 1.592 \\
\hline & & & Outros... & $\ldots$ & $\ldots$ \\
\hline
\end{tabular}


Internacionalização da educação superior: uma análise das tendências de mobilidade dos estudantes entre países do norte e do sul global

\begin{tabular}{|c|c|c|c|c|c|}
\hline & & & Brasil & 331 & 122 \\
\hline \multirow[t]{10}{*}{ Alemanha } & \multirow{5}{*}{$\begin{array}{c}\mathbf{2 0 1 0} \\
120.280 \\
\text { OCDE } \\
+ \\
2.948 \\
\text { G20 }\end{array}$} & \multirow{5}{*}{$\begin{array}{c}\mathbf{2 0 1 0} \\
144.911 \\
\text { OCDE } \\
+ \\
48.083 \\
\text { G20 } \\
+ \\
95.525 \\
\text { Demais países }\end{array}$} & Turquia & 29.873 & 728 \\
\hline & & & Polônia & 12.350 & 682 \\
\hline & & & Itália & 8.857 & 1.520 \\
\hline & & & Áustria & 8.245 & 27.150 \\
\hline & & & Holanda & 22.066 & 23.579 \\
\hline & \multirow{5}{*}{$\begin{array}{c}\mathbf{2 0 1 4} \\
116.342\end{array}$} & \multirow{5}{*}{$\begin{array}{c}\mathbf{2 0 1 4} \\
228.756\end{array}$} & Reino Unido & 20.157 & 13.846 \\
\hline & & & Suíça & 13.811 & 11.742 \\
\hline & & & Estados Unidos & 9.463 & 7.137 \\
\hline & & & Outros... & & $\ldots$ \\
\hline & & & Brasil & 275 & 318 \\
\hline \multirow[t]{8}{*}{ China } & \multirow{4}{*}{$\begin{array}{c}\mathbf{2 0 1 0} \\
534.179 \\
\text { OCDE } \\
+ \\
102.176 \\
\text { G20 }\end{array}$} & \multirow[t]{4}{*}{2010} & Estados Unidos & 126.498 & 291.063 \\
\hline & & & Austrália & 87.588 & $\mathbf{9 7 . 3 8 7}$ \\
\hline & & & Reino Unido & 62.309 & 86.204 \\
\hline & & & Japão & 86.553 & 85.226 \\
\hline & \multirow{4}{*}{$\begin{array}{c}\mathbf{2 0 1 4} \\
801.187\end{array}$} & \multirow{4}{*}{$\begin{array}{c}\mathbf{2 0 1 4} \\
123.127\end{array}$} & Canada & 35.592 & 42.011 \\
\hline & & & Coreia & 45.757 & 34.513 \\
\hline & & & Outros & $\ldots$ & $\ldots$ \\
\hline & & & Brasil & 354 & 332 \\
\hline
\end{tabular}

Fonte: Elaborado pelos autores com base nos dados da UNESCO (2015) e da OCDE (2012).

Na tabela 1, divulgamos os números referentes aos estudantes de alguns dos países com maior mobilidade acadêmica estudantil em 2010 e em 2014. São eles Estados Unidos, Reino Unido, Alemanha e China.

No caso dos Estados Unidos, o país enviou significativamente menos estudantes do que recebeu. $\mathrm{O}$ número de estudantes estadunidenses que foram estudar no exterior em 2010 foi DE 52.569 e, destes, percebe-se uma preferência por sua recepção nos países da OCDE, num total de 50.756 alojados nesses países desenvolvidos e mais 1.813 em países do G20.

Quanto à recepção de estudantes estrangeiros para estudar nos Estados Unidos, percebe-se que os estudantes vêm de todos os grupos, de países desenvolvidos e em desenvolvimento. Dessa forma, os Estados Unidos, em 2010, receberam 212.835 estudantes dos países da OCDE, 270.298 estudantes dos países que compõe o G20, e 174.742 dos demais países, totalizando 657.875 estudantes recebidos no país.

Em 2014, o país segue a mesma lógica, oferecendo a 67.665 estudantes estudar no exterior e recebendo 907.251 estudantes estrangeiros, o que significa que o país oferece aos países apenas $7,45 \%$ do que arrecada.

O Reino Unido também se apresenta como um país que oferece muito menos estudantes do que recebe. Em 2010, 33.495 estudantes do Reino Unido foram estudar em 
países da OCDE, e 1.813 nos países em desenvolvimento que compõem o G20, totalizando 35.308 estudantes no exterior. No entanto, 198.431 estrangeiros foram estudar no Reino Unido, vindos de países desenvolvidos como a Alemanha, a Irlanda, a França, os Estados Unidos, 130.942 vindos dos países do G20 e 198.916 vindos de outros países. Estes números somam 528.289 estudantes recebidos para estudar neste país, o que significa que o Reino Unido oferece apenas 6,34\% do seu contingente de educandos em relação ao que recebe.

Em 2014, o Reino Unido segue oferecendo consideravelmente menos estudantes de intercâmbio do que recebendo. Enviou 31.078, o que significa 7,24\% em relação ao referente recebido de 428.724 estudantes. A Alemanha também é um país que tem um importante movimento de saída de estudantes para o exterior e recepção de estudantes estrangeiros para estudar nas suas universidades.

Em 2010, o país enviou 120.280 jovens para estudar nos países que compõem a OCDE e 2.948 para os países do G20. No entanto, recebeu para estudar em suas instituições de Educação Superior 144.911 estudantes vindos dos países da OCDE, 48.083 vindos dos países do G20 e 95.525 estudantes vindos dos demais países, recebendo no total 288.519 estudantes estrangeiros. O que difere os dois exemplos anteriores, o exemplo da Alemanha é que o número de estudantes enviados para o exterior é de 43,7\% do número de estudantes recebidos pelo país, o que demonstra mais equilíbrio e simetria no intercâmbio.

A Alemanha, em 2014, recebeu 116.342 e enviou 228.756, mantendo um percentual de $50,85 \%$ entre os estudantes enviados e os recebidos para realizar o intercâmbio.

O 4. ${ }^{\circ}$ exemplo é o da China, que não é um país considerado desenvolvido, mas é um país que compõe o G20. O exemplo da China também é significativo, uma vez que é o país que mais estudantes tem enviado para estudar no exterior, fazendo o processo contrário ao dos países da OCDE.

Em 2010, a China enviou 534.179 estudantes para estudar nos países que compõem a OCDE, e 102.176 estudantes para estudar nos países do G20, totalizando 636.355. A sua preferência são os países de língua inglesa, como Estados Unidos, Austrália, Canadá e Reino Unido, e os países asiáticos, como o Japão e a Coreia. Por outro lado, o número de estudantes que tem a China como opção é bem menor do que os que o país oferece.

Em 2014, o número de estudantes chineses que estudaram no exterior aumentou ainda mais, passando para um total de 801.187 acadêmicos em mobilidade; receberam, no entanto, apenas $15,36 \%$ em relação aos estudantes enviados ao exterior. Foram 123.127 estudantes para alojarem-se na China. 
Internacionalização da educação superior: uma análise das tendências de mobilidade dos estudantes entre países do norte e do sul global

Pode-se perceber que os países têm preferência por enviar seus estudantes para os Estados Unidos ou países da Europa. Os Estados Unidos também procuram enviar o maior número de seus estudantes para os países europeus.

Segundo Lima \& Maranhão (2009), para que não pairem dúvidas acerca do volume de investimento requerido pelos programas de emissão de estudantes, "chama-se atenção para a ausência de regiões e países mais carentes entre aqueles que estão mais bem representados na estatística da mobilidade estudantil passiva. Essa evidência aponta que o atual modelo de internacionalização favorece aqueles países que podem pagar por ele ou que recebem pelo serviço prestado".

A tabela 2 nos mostra como ocorre essa mobilidade estudantil quando envolve o Brasil, o país maior em área sul americana e, junto com México, um dos dois países academicamente maiores em América Latina e o Caribe.

Em 2010, o Brasil enviou 30.906 para os países que compõem a OCDE e 3.604 para os países que compõem o G20, enviando um total de 34.510 acadêmicos. Por outro lado, recebeu 3.937 intercambistas vindos de países considerados desenvolvidos, 1.347 de países considerados em desenvolvimento e 7.495 dos demais países, totalizando 12.779. No caso dos brasileiros, o país mais procurado é os Estados Unidos, de língua inglesa, pela necessidade de aprender a Língua e, em 2. ${ }^{\circ}$ lugar, Portugal, pela facilidade na comunicação em língua portuguesa.

Tabela 2 - Simetria entre estudantes brasileiros no exterior e estudantes estrangeiros recebidos no Brasil - 2010 e 2014

\begin{tabular}{|c|c|c|c|c|c|}
\hline \multirow{17}{*}{ Brasil } & \multirow{2}{*}{$\begin{array}{c}\begin{array}{c}\text { N.o estudantes } \\
\text { Enviados para o } \\
\text { Exterior }\end{array} \\
2010\end{array}$} & \multirow{2}{*}{$\begin{array}{c}\mathrm{N}^{\circ} \\
\text { estudantes } \\
\text { Recebidos no } \\
\text { Brasil } \\
2010\end{array}$} & \multicolumn{2}{|c|}{$\begin{array}{c}\text { Países que mais recebem } \\
\text { estudantes brasileiros } \\
\text { em } 2010\end{array}$} & \multirow{2}{*}{$\begin{array}{r}\begin{array}{c}\text { N. }{ }^{\circ} \text { estudantes que } \\
\text { o Brasil recebeu } \\
\text { desses países }\end{array} \\
424 \\
\end{array}$} \\
\hline & & & Estados Unidos & 8.708 & \\
\hline & \multirow{7}{*}{$\begin{array}{c}30.906 \\
\text { OCDE } \\
+ \\
3.604 \\
\text { G20 }\end{array}$} & \multirow{7}{*}{$\begin{array}{c}3.937 \\
\text { OCDE } \\
+ \\
1.347 \\
\text { G20 } \\
+ \\
7.495 \\
\text { Demais países }\end{array}$} & Portugal & 4.421 & 830 \\
\hline & & & Espanha & 3.423 & 199 \\
\hline & & & França & 3.540 & 346 \\
\hline & & & Alemanha & 2.586 & 275 \\
\hline & & & Reino Unido & 2.422 & 331 \\
\hline & & & Austrália & 776 & 18 \\
\hline & & & Outros & $\ldots$ & ... \\
\hline & \multirow{8}{*}{$\begin{array}{c}\mathbf{2 0 1 4} \\
40.891\end{array}$} & \multirow{8}{*}{$\begin{array}{c}\mathbf{2 0 1 4} \\
19.855\end{array}$} & Estados Unidos & 13.349 & 663 \\
\hline & & & Portugal & 5.438 & 806 \\
\hline & & & Espanha & 1.346 & 273 \\
\hline & & & França & 4.032 & 330 \\
\hline & & & Alemanha & 3.790 & 318 \\
\hline & & & Reino Unido & 2.184 & 122 \\
\hline & & & Austrália & 1.554 & 20 \\
\hline & & & Outros & $\ldots$ & $\ldots$ \\
\hline
\end{tabular}

Fonte: Elaborado pelos autores com base nos dados da UNESCO (2015) e OCDE (2012). 
O Brasil, em 2010, recebeu apenas $37 \%$ de estudantes em relação aos enviados para o exterior.

No entanto, em 2014, esse percentual passou para 48,44\%, pois foram enviados 40.981 brasileiros para estudar, principalmente nos países desenvolvidos, e 19.855 estudantes estrangeiros vieram estudar no Brasil (Tabela 2).

Segundo Lima \& Maranhão (2009, p. 588), “como associar a internacionalização da Educação Superior a processos de integração, baseados na solidariedade e na cooperação internacional, quando os recursos humanos e materiais provenientes dos países da periferia da economia do mundo ajudam a financiar a educação dos países centrais?”. E dizem ainda que "tais condições contribuem para a emergência do que Boaventura de Sousa Santos (2002), António Teodoro (2003) e Roger Dale (2004) nomeiam de 'globalização hegemônica"”.

Analisando a tabela 3, temos os dados dos estudantes vindos dos países de Língua Portuguesa para o Brasil (membros da Comunidade de Países de Língua Portuguesa - CPLP), como Angola, Cabo Verde, Guiné-Bissau, Portugal, Moçambique, Timor Leste e São Tomé e Príncipe. O país que mais enviou estudantes para o exterior foi Portugal, seguido de Angola. No entanto, o país que teve um percentual de estudantes maior enviado ao Brasil em relação ao número de estudantes no exterior foi Guiné-Bissau, com $23 \%$ dos seus intercambistas estudando no Brasil. Angola, embora tenha enviado um número maior - 1.631 estudantes -, teve um percentual inferior de $14 \%$ se comparado à Guiné-Bissau. Portugal enviou apenas $3,7 \%$ dos seus intercambistas para o Brasil.

Tabela 3 - Mobilidade total e no Brasil dos países da CPLP

\begin{tabular}{c|r|r|r|r|r|r}
\hline & \multicolumn{3}{|c|}{$\mathbf{2 0 1 0}$} & \multicolumn{3}{|c}{$\mathbf{2 0 1 4}$} \\
\hline & $\begin{array}{c}\text { Total de } \\
\text { estudantes } \\
\text { enviados } \\
\text { pelo país }\end{array}$ & $\begin{array}{c}\text { Estudantes } \\
\text { recebidos } \\
\text { no } \\
\text { Brasil }\end{array}$ & $\%$ & $\begin{array}{c}\text { Total de } \\
\text { estudantes } \\
\text { enviados } \\
\text { pelo país }\end{array}$ & $\begin{array}{c}\text { Estudantes } \\
\text { recebidos } \\
\text { no } \\
\text { Brasil }\end{array}$ & $\%$ \\
\hline Angola & 11.678 & 1.631 & $14 \%$ & 11.654 & 2.317 & $19,88 \%$ \\
\hline Cabo Verde & 8.897 & 892 & $10 \%$ & 3.031 & 623 & $20,55 \%$ \\
\hline Guiné-Bissau & 3.601 & 830 & $23 \%$ & 1.958 & 953 & $48,67 \%$ \\
\hline Portugal & 22.136 & 830 & $3,7 \%$ & 12.267 & 806 & $6,57 \%$ \\
\hline Moçambique & 4.161 & 122 & $3 \%$ & 2.271 & 328 & $14,44 \%$ \\
\hline Timor Leste & 6.012 & 6 & $1 \%$ & 3.882 & 190 & $4,89 \%$ \\
\hline São Tomé e Príncipe & 4.337 & 100 & $2,3 \%$ & 730 & 136 & $18,63 \%$ \\
\hline
\end{tabular}

Fonte: Elaborado pelos autores com base nos dados da UNESCO (2015) e OCDE (2012).

Na comparação de 2010 para 2014, todos os países de língua portuguesa diminuíram em aproximadamente $50 \%$ o seu número de estudantes no exterior, com exceção de Angola, 
Internacionalização da educação superior: uma análise das tendências de mobilidade dos estudantes entre países do norte e do sul global

que mantém estável esse número. No entanto, analisando o quadro, todos os percentuais de acadêmicos estudando no Brasil aumentaram, sendo opção para mais estudantes, inclusive de Portugal que, embora tenha diminuído de 22.136 para 12.267 o seu contingente no exterior, o percentual de estudantes no Brasil aumentou de 3,7\% para 6,57\%. A Guiné-Bissau também aumentou de $23 \%$ para $48,67 \%$ os estudantes enviados para o Brasil.

Na tabela 4, pode-se analisar a relação do Brasil com os países da América do Sul em termos de mobilidade.

Tabela 4 - Mobilidade total e no Brasil dos países da América do Sul

\begin{tabular}{|c|c|c|c|c|c|c|}
\hline & $\begin{array}{l}\text { Total de } \\
\text { estudantes } \\
\text { enviados } \\
\text { pelo país } \\
\text { ao } \\
\text { exterior }\end{array}$ & $\begin{array}{c}\text { Estudantes } \\
\text { recebidos } \\
\text { no Brasil }\end{array}$ & $\%$ & $\begin{array}{c}\text { Total de } \\
\text { estudantes } \\
\text { enviados } \\
\text { pelo país } \\
\text { ao } \\
\text { exterior }\end{array}$ & $\begin{array}{c}\text { Estudantes } \\
\text { recebidos } \\
\text { no Brasil }\end{array}$ & $\%$ \\
\hline & \multicolumn{3}{|c|}{2010} & \multicolumn{3}{|c|}{2014} \\
\hline Argentina & 13.582 & 757 & $5,57 \%$ & 8.255 & 1.061 & $12,85 \%$ \\
\hline Bolívia & 15.502 & 383 & $2,47 \%$ & 9.966 & 858 & $8,6 \%$ \\
\hline Chile & 11.631 & 445 & $3,82 \%$ & 9.270 & 522 & $5,63 \%$ \\
\hline Colômbia & 29.998 & 260 & $0,8 \%$ & 28.122 & 1.627 & $5,78 \%$ \\
\hline Equador & 14.380 & 121 & $0,8 \%$ & 13.910 & 329 & $2,36 \%$ \\
\hline Guiana & 1.283 & 17 & $1,32 \%$ & 1.487 & 5 & $0,33 \%$ \\
\hline Paraguai & 4.047 & 536 & $13,24 \%$ & 3.424 & 1.082 & $31,60 \%$ \\
\hline Peru & 22.598 & 552 & $2,44 \%$ & 16.528 & 1.409 & $8,52 \%$ \\
\hline Suriname & 1.165 & 3 & $0,25 \%$ & 896 & 5 & $0,5 \%$ \\
\hline Uruguai & 4.201 & 407 & $9,68 \%$ & 2.521 & 592 & $23,48 \%$ \\
\hline Venezuela & 18.048 & 125 & $0,6 \%$ & 16.810 & 286 & $1,7 \%$ \\
\hline
\end{tabular}

Fonte: Elaborado pelos autores com base nos dados da UNESCO (2015) e OCDE (2012).

Pode-se perceber que em 2010 o país da América do Sul que mais enviou estudantes para estudar no exterior foi a Colômbia (29.998), seguido do Peru (22.598). Desses contingentes, os percentuais de estudantes enviados ao Brasil foram de 0,8\% e 2,44\%, respectivamente.

O país que mais encaminhou estudantes, em números, para o Brasil, foi a Argentina, com 757 estudantes, porém seu percentual em relação ao total de intercambistas argentinos foi apenas de 5,57\%. O país com o percentual mais alto de intercambistas no Brasil foi o Paraguai, que, em relação ao número total de estudantes no exterior (4.047), 536 estudantes, o que significa $13,24 \%$, vieram para o Brasil.

Realizando essa mesma análise em 2014, verifica-se que todos os países diminuíram o número de estudantes em intercâmbio no exterior, configurando-se uma diminuição pouco 
significativa. A exceção foi da Guiana, que aumentou em 200 estudantes o seu contingente no exterior.

O país que mais procurou o Brasil para os seus estudantes foi a Colômbia (1.627), porém, em relação ao seu número total de intercambistas no exterior (29.998), isso significa apenas 5,78\%. O país que tem uma relação maior entre os estudantes enviados para o exterior e os enviados ao Brasil segue sendo o Paraguai, com 31,60\%, seguido do Uruguai, com $23,48 \%$ dos seus estudantes.

Tendo como exemplo os valores de uma bolsa para graduação sanduíche do Brasil no exterior, os valores e despesas de auxílio para o bolsista são as seguintes:

\section{Tabela 5 - Valores de auxílios e bolsas do Ciências sem Fronteira Brasil}

\begin{tabular}{l|c|c}
\hline \multicolumn{1}{c|}{ Despesas } & $\begin{array}{c}\text { Estados } \\
\text { Unidos/ } \\
\mathbf{1} \text { ano } \\
\text { (dólar) }\end{array}$ & $\begin{array}{c}\text { Europa/ } \\
\mathbf{1} \text { ano } \\
\text { (euro) }\end{array}$ \\
\hline Mensalidade & $10.440,00$ & $10.440,00$ \\
\hline Cidade de alto custo & $4.800,00$ & $4.800,00$ \\
\hline Alojamento alimentação & $3.600,00$ & $3.600,00$ \\
\hline Seguro Saúde & $1.080,00$ & $1.080,00$ \\
\hline Auxílio instalação & $1.320,00$ & $1.320,00$ \\
\hline Material didático & $1.000,00$ & $1.000,00$ \\
\hline Auxílio deslocamento & $1.604,00$ & $1.706,00$ \\
\hline Total & $23.844,00$ & $23.946,00$ \\
\hline
\end{tabular}

Fonte: Elaborado pelos autores com apoio do Ministério da Educação e Cultura, Ciência sem Fronteiras (BRASIL, 2017).

Se levarmos em consideração os valores simulados na tabela 5 , pois eles são uma estimativa - uma vez que há mais impostos que incidem sobre os valores -, temos uma comparação parcial entre os valores que o Brasil investe e os valores que o Brasil arrecada para a mobilidade de estudantes no processo de internacionalização do ES.

Alguns autores preocupam-se ainda com outros fatores, que:

[...] frente ao grande apelo à mobilidade internacional de estudantes e pesquisadores inserida nas discussões sobre a importância da internacionalização da educação superior, a questão posta no cenário internacional está assentada sobre se essa referida mobilidade representa um jogo competitivo de ganho ou perda de cérebros. A pergunta é se existem claros ganhadores e perdedores ou se essa movimentação global de acadêmicos seria melhor caracterizada como circulação de cérebros, onde os ganhos e perdas seriam idealmente mais equanimemente distribuídos, tendo em vista a circulação e retroalimentação do conhecimento por ela proporcionada (De WIT 2008 apud LAUS, 2012, p. 152). 
Internacionalização da educação superior: uma análise das tendências de mobilidade dos estudantes entre países do norte e do sul global

No entanto, no caso brasileiro, o programa Ciência sem Fronteiras é uma bolsa de estudos que tem como critério o retorno do estudante para finalizar o curso de graduação no Brasil. Esse retorno dificulta para os bolsistas que realizaram a experiência no exterior seguir com vínculos profissionais internacionais por motivos pessoais, financeiros, entre outros.

Outra crítica enfrentada fortemente pelo Programa é que os bolsistas que retornam para o Brasil com suas experiências significativas não encontram espaço institucional para divulgar o que aprenderam em nível profissional, acadêmico, pessoal, cultural, tornando esta uma experiência importante muitas vezes apenas para o próprio sujeito/bolsista - e, do ponto de vista financeiro, para o país que o recebeu.

Tabela 6 - Simulação dos valores aportados por estudantes brasileiros no exterior e por estrangeiros no Brasil

\begin{tabular}{c|c|c|c|c}
\hline $\begin{array}{c}\text { Estudantes } \\
\mathbf{2 0 1 0}\end{array}$ & $\begin{array}{c}\text { Estados } \\
\text { Unidos } \\
\text { (Dólar) }\end{array}$ & $\begin{array}{r}\text { Portugal } \\
\text { (Euro) }\end{array}$ & $\begin{array}{r}\text { Espanha } \\
\text { (Euro) }\end{array}$ & Total \\
\hline Número de brasileiros & 8.708 & 4.421 & 3.423 & \\
\hline $\begin{array}{c}\text { Valores simulados } \\
\begin{array}{c}\text { Número de estrangeiros } \\
\text { recebidos }\end{array}\end{array}$ & $207.633 .552,00$ & $105.865 .266,00$ & $81.967 .158,00$ & $395.465 .976,00$ \\
\hline $\begin{array}{c}\text { Valores simulados } \\
\text { Total diferença }\end{array}$ & $10.109 .856,00$ & $19.875 .180,00$ & $4.765 .254,00$ & $34.750 .290,00$ \\
\hline
\end{tabular}

Fonte: Elaborada pelos autores com base nos valores do Ciências sem Fronteira (BRASIL, 2017).

A partir dos valores simulados com os 3 países que mais recebem estudantes brasileiros e comparando-se com o retorno que esses mesmos países oferecem, enviando seus estudantes para estudar no Brasil, confirma-se que os recursos brasileiros enviados para os países da OCDE são imensamente maiores do que os recebidos.

O fenômeno da internacionalização da educação superior e consequentemente da internacionalização do capital nacional confirma que a educação superior tornou-se um mercado vantajoso do ponto de vista econômico, mas em especial para os países desenvolvidos. Por mais que exista determinada vantagem para os países em desenvolvimento que enviam seus jovens para estudar no exterior, essas vantagens são menos significativas do que os prejuízos econômicos que os países mais podres têm ao enviar milhões para os países ricos. 


\section{Considerações finais}

O estudo desenvolvido permite confirmar uma vez mais o que outros estudos têm mostrado e vai além, pois apresenta números disponíveis nas plataformas oficiais das agências internacionais e nacionais.

Foi possível perceber que os Estados Unidos continuam a desempenhar uma posição central nos fluxos e tendências da mobilidade internacional de estudantes de educação superior, concentrando no seu sistema estudantes de diversas regiões globais e grupos de países. No entanto, sua retribuição com o número total de estudantes estadunidenses encaminhados para outros países verifica-se limitada, em especial para os países do hemisfério sul. Já em 2014, os Estados Unidos superavam a cifra de 900 mil estudantes internacionais nas suas instituições, hoje chegando esse número a mais de 1 milhão de estudantes.

O Reino Unido também se apresenta como um país com um saldo positivo na recepção de estudantes internacionais, com quase meio milhão de estudantes internacionais. Apenas 30 mil dos seus cidadãos, no entanto, encaminham-se para outros países, em geral vizinhos e semelhantemente desenvolvidos, pertencentes a OCDE. As origens dos estudantes internacionais no Reino Unido são principalmente das nações da OCDE e daqueles países que compunham o antigo Commonwealth ou mantinham relações coloniais e/ou de dependência.

Em contraste com os Estados Unidos e Inglaterra, principais atores da mobilidade internacional de estudantes de nível terciário, Alemanha apresenta um equilíbrio maior e um balanço menor, embora possua também um saldo positivo, o que se explica em parte por razões linguísticas.

O caso da China, um poder econômico e científico-tecnológico emergente, é exatamente o contrário dos casos dos países anglo-saxônicos e da Alemanha. Enquadra-se na tendência geral do mundo em desenvolvimento, pois contribui com um número significativo do total dos estudantes internacionais que se orientam aos países desenvolvidos da OCDE e da região asiática (Japão e Coreia).

Nos casos dos países da CPLP e da América do Sul, na sua relação com Brasil - o principal produtor acadêmico na América do Sul e o segundo na CPLP -, os dados permitem também identificar os sinais de uma orientação preferencial para o hemisfério norte como destino da mobilidade internacional. Essa orientação é, por outra parte, também a tendência hegemônica no Brasil, como se percebe na orientação principal da mobilidade de estudantes 
Internacionalização da educação superior: uma análise das tendências de mobilidade dos estudantes entre países do norte e do sul global

desde e até o Brasil e na pauta de financiamento da mobilidade de estudantes brasileiros, principalmente nas bolsas do programa Ciência sem Fronteiras.

A participação relativa das regiões do sul é relevante como provedores de mobilidade de estudantes, mas muito limitada em termos de pontos de destino. O Sul Global ainda parece manter seu foco no Norte Global.

Se essa pauta geral fosse confrontada com uma formulação política ideal que operasse como fundamento dela, então deveríamos concluir que as políticas públicas que promovem a internacionalização ainda não percebem a relevância de novas configurações possíveis nos fluxos da mobilidade de estudantes e continuam focadas na formação de recursos humanos nos centros internacionais de desenvolvimento científico. Boa ou ruim, essa política deveria gerar efeitos benéficos nos sistemas de educação superior de chegada - principalmente em termos econômicos e de soft power - e possivelmente altas taxas de retorno individual do investimento na formação científica no exterior. No entanto, as externalidades econômicas ou outros efeitos benéficos nos sistemas de educação superior da América do Sul, e do Brasil, ainda deveriam ser avaliados, pois os ganhos com a imersão no contexto universitário e científico internacional têm-se reduzido à experiência pessoal do estudante, pouco usufruída pela comunidade universitária e científica.

Com base na descrição e na discussão das tendências encontradas, o artigo permitenos concluir que a mobilidade internacional no Brasil, e na região latino-americana, ainda está predominantemente baseada na relação Norte-Sul, e que os mecanismos de mobilidade criados nos países do Sul não estão baseados em estratégias consistentes de internacionalização ou regionalização, resultando em mais uma estratégia de transferência de recursos significativos, em especial econômicos, mas não só, dos países menos desenvolvidos para os países desenvolvidos.

Em outro aspecto, o estudo desmistifica alguns efeitos deletérios e a propaganda governamental sobre benefícios de determinadas políticas públicas de educação superior, em especial, de internacionalização com destaque para a mobilidade internacional e confirma que a internacionalização da educação superior está inserida na ótica neoliberal de internacionalização/globalização do capital sendo a educação superior uma parte dessa engrenagem - um mercado vantajoso, do ponto de vista econômico, para os países desenvolvidos.

A relevância se observa nos argumentos empregados para comprovar que a política pública de internacionalização, de um país emergente, precisa ser bem pensada e elaborada antes de tornar-se um prejuízo aos cofres públicos. Afinal, pergunta-se, - por que o rigor da 
avaliação da pesquisa e da pós-graduação no Brasil? Não seriam nossas universidades suficientemente adequadas para formar graduandos? Nossos estudantes precisam ser enviados ao exterior sem que recebamos a contrapartida de recepção dos estudantes estrangeiros em nosso país? O artigo comprova que, sob o ponto de vista econômico-financeiro, o país criou uma dívida a fundo perdido. O artigo comprova que o país investiu em universidades estrangeiras deixando de fazê-lo, por exemplo, no seu próprio sistema público de educação superior.

Embora essa relação não seja um achado novo, permite a confirmação das linhas mestres de uma geopolítica do conhecimento baseada na hegemonia dos sistemas de educação superior, ciência, tecnologia e inovação dos países desenvolvidos nord-ocidentais, e a ausência relativa de políticas de internacionalização tendentes à revisão desses fluxos.

\section{Referências}

AYLLÓN, Bruno Pino. La cooperación de Brasil: un modelo en construcción para una potencia emergente. 2010. Disponível em: <http://www.cedep.ifch.ufrgs.br/elcano.pdf > Acesso em: 15 out. 2017.

BRASIL. Ministério da Educação e Cultura. Programa Ciência sem Fronteiras. Disponível em: < http://www.cienciasemfronteiras.gov.br/web/csf/valores-de-auxilios-e-bolsas> Acesso em: 13 jun. 2017.

CINDA. Informe de Educação Superior em Ibero-américa. Santiago de Chile. 2016. Disponível em: <http://www.cinda.cl/2016/11/16/informe-educacion-superior-eniberoamerica-2016/\#more> Acesso em: 28 nov. 2017.

DALE, Roger. Globalização e educação: demonstrando a existência de uma 'cultura educacional mundial comum' ou localizando uma 'agenda globalmente estruturada para a Educação. Educação \& Sociedade, Campinas, v. 25, n. 87, p. 423-460, maio/ago. 2004.

FERNÁNDEZ LAMARRA, Norberto; ALBORNOZ, Mario. La internacionalización de la Educación Superior y la Ciencia en Argentina. In: AUPETIT, Sylvie Didou; ESCOBAR, Vielka Jaramillo de (Coords.). Internacionalización de la Educación Superior y la Ciencia en América Latina y el Caribe: un Estado del ARTE. Caracas: UNESCO-IESALC, 2014.

HARGREAVES, Andy. Ensino na sociedade de conhecimento: educação na era da insegurança. Porto Alegre: Artes Médicas, 2003.

KNIGHT, Jane. Student Mobility and Internationalization: trends and tribulations. Research in Comparative and International Education, Oxford, n. 7, v. 1, 2012.

LAUS, Simone P. A internacionalização da educação superior: um estudo de caso da Universidade Federal de Santa Catarina. 2012. Tese (Doutorado em Administração) Universidade Federal da Bahia, Salvador, 2012. 
Internacionalização da educação superior: uma análise das tendências de mobilidade dos estudantes entre países do norte e do sul global

LIMA, Manolita Correia; MARANHÃO, Carolina Machado S. A. O Sistema de Educação Superior Mundial: entre a internacionalização Ativa e Passiva. Avaliação, Campinas;

Sorocaba, SP, v. 14, n.3, p. 583-610, nov. 2009.

OCDE. Education at a Glance. 2012. Disponível em:

<http://www.oecd.org/edu/highlights.pdf>. Acesso em: 13 jun. 2017.

SANTOS, Boaventura Sousa. Os processos da globalização. In: SANTOS, Boaventura Sousa (Org.). Globalização: fatalidade ou utopia? 2. ed. Porto: Afrontamento, 2002. p. 31-106.

TEODORO, António. Globalização e educação: políticas educacionais e novos modos de governação. São Paulo: Cortez, 2003.

UNESCO. Instituto de Estatística. Fluxo global de estudantes de nível terciário. 2010.

Disponível em: <http://uis.unesco.org/en/uis-student-flow\#slideoutsearch〉. Acesso em: 13 jun. 2017.

UNESCO. Instituto de Estatística. Crescimento de longo prazo dos estudantes

internacionais de terceiro nível 1975-2013. 2015. Disponível em:

$<$ https://en.unesco.org/sites/default/files/1-4_growth_international_students.pdf >. Acesso em: 13 jun. 2017.

${ }^{1}$ Marialva Moog Pinto Universidade da Região de Joinville (Univille) | Programa de Mestrado em Educação Joinville | SC | Brasil. Contato: marialvamoog@ hotmail.com ORCID iD orcid.org/0000-0002-9898-8576

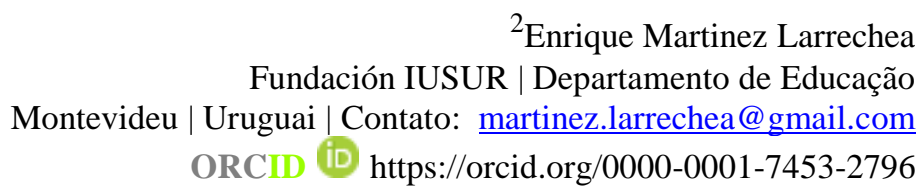

Artigo recebido em 3 de janeiro de 2018 e aprovado em 27 de julho de 2018 . 